\title{
Aktivitas Antibakteri Kain Poliester dengan Penambahan Heksadesiltrimetoksisilan (HDTMS) terhadap Staphylococcus aureus ATCC 25924
}

\section{Antibacterial Activity of Polyester Fabric with Addition of Hexadecyltrimethoxysilane (HDTMS) against Staphylococcus aureus ATCC 25924}

\author{
Eli Rohaeti, Nur Ihda Zulaikha \\ Jurusan Pendidikan Kimia, FMIPA, Universitas Negeri Yogyakarta, 55281 \\ E-mail:eli_rohaeti@uny.ac.id
}

\begin{abstract}
Abstrak
Penelitian ini bertujuan untuk mengetahui aktivitas antibakteri kain poliester yang terdeposit senyawa HDTMS (P-HDTMS) terhadap bakteri Staphylococcus aureus ATCC 25924. Larutan HDTMS dibuat dengan melarutkan senyawa HDTMS dalam etanol 4\%. Larutan HDTMS kemudian didepositkan pada sampel kain Poliester. Uji aktivitas antibakteri P-HDTMS dilakukan melalui metode difusi dengan mengukur diameter zona bening di sekitar sampel. Hasil penelitian menunjukkan bahwa senyawa HDTMS telah terdeposit pada kain poliester. Hasil uji zona bening menunjukkan bahwa P-HDTMS memiliki diameter zona bening sebesar $9.25 \mathrm{~mm}$ pada waktu inkubasi selama 60 jam. Dengan demikian P-HDTMS mempunyai aktivitas antibakteri dalam menghambat pertumbuhan bakteri Staphylococcus aureus ATCC 25924.
\end{abstract}

Kata kunci: Antibakteri, heksadesiltrimetoksisilan, kain polyester, Staphylococcus aureus ATCC 25924.

\begin{abstract}
This research aims to determine the antibacterial activity of polyester which was deposited by hexadecyltrimethoxysilane (HDTMS) against bacteria Staphylococcus aureus ATCC 25924. The HDTMS solution was made by dissolving the HDTMS compound in $4 \%$ ethanol. The HDTMS solution was then deposited on a polyester fabric sample. The antibacterial activity test of P-HDTMS was conducted with diffusion method by measuring the diameter of clear zone around the sample. The results of this research showed that HDTMS compound has been deposited on polyester fabrics. The clear zone test results showed that P-HDTMS has diameter of clear zone of $9.25 \mathrm{~mm}$ at incubation time of 60 hours. Thus, P-HDTMS has an antibacterial activity against Staphylococcus aureus ATCC 25924.
\end{abstract}

Keywords: Antibacterial, hexadecyltrimethoxysilane, polyester fabrics, Staphylococcus aureus ATCC 25924.

DOI: http://dx.doi.org/10.15408/jkv.v3i2.5831

\section{PENDAHULUAN}

Kebutuhan akan tekstil merupakan kebutuhan primer bagi seluruh masyarakat. Tekstil yang memiliki kualitas bagus seperti kain antikotor dan antibakteri masih sangat jarang bahkan belum diproduksi oleh negeri kita sendiri. Dengan demikian diperlukan suatu inovasi baru untuk menciptakan suatu bahan tekstil misalnya poliester, katun, dan nylon dengan kualitas bagus dan memiliki sifat antibakteri yang dapat diproduksi oleh negara kita sendiri. Bahan antibakteri dapat dikembangkan dengan cara mengaplikasikan 
nanoteknologi (Ariyanta et al., 2014; ElKhatib, 2012; Rohaeti dan Rakhmawati, 2017) atau dengan melapisi permukaan bahan tekstil dengan senyawa silan.

Penambahan molekul berbasis silan seperti senyawa heksadesiltrimetoksisilan (HDTMS) dapat memberi suatu energi bebas permukaan yang sangat rendah terhadap permukaan kain yang diproses dengan senyawa tersebut. Energi permukaan menyebabkan tegangan permukaan semakin kecil menyebabkan sudut kontak semakin besar sehingga dapat menyebabkan sifat hidrofobik. Bahan dengan sifat hidrofobik kemungkinan memiliki sifat antibakteri, karena bakteri seringkali dapat hidup atau tumbuh dengan baik di daerah atau bahan yang hidrofilik. Dengan demikian mikroorganisme sulit hidup pada bahan hidrofobik. Beberapa jenis senyawa silan telah digunakan untuk memodifikasi tekstil adalah octyltrithoxysilane (OTES) (Shateri-Khalilabad dan Yazdanshenas, 2010), polimetilhidroksilosan (PMHS) dan tetraethoxysilane (TEOS), metiltrimetoksisilan (MTMS), serta heksadesiltrimetoksisilan (HDTMS) (Xue et al., 2012).

Heksadesiltrimetoksisilan merupakan salah satu senyawa turunan silan yang memiliki gugus alkoksida dan panjang rantaialkil sebanyak 16 atom karbon. Senyawa ini memiliki kemampuan untuk menurunkan energi permukaan pada suatu material. Penurunan energi permukaan akan mengakibatkan permukaan material akan memiliki sudut kontak yang semakin besar (Shateri-Khalilabad dan Yazdanshenas, 2013). Selain itu, senyawa HDTMS memiliki struktur yang sama dengan struktur detergen. Sebagaimana diungkapkan oleh Rama et al., (2011) bahwa detergen memiliki sifat antibakteri. Dengan demikian pada penelitian ini, aktivitas antibakteri HDTMS yang dilapiskan pada kain poliester dipelajari.

Senyawa HDTMS secara kimia terikat dengan bahan melalui reaksi kondensasi permukaan. Penambahan senyawa HDTMS pada kain poliester terdeposit nano partikel diharapkan mampu meningkatkan kualitas bahan poliester agar bersifat hidrofobik dan antibakteri. Senyawa silan ini merupakan senyawa serba guna yang digunakan pada berbagai bidang seperti adhesi promoters, coupling agent, crosslinking agent, dispersing agents, dan surface modifiers (Arkles, 2006;
Shateri-Khalilabad dan Yazdanshenas, 2010 dan 2013). Modifikasi Poli vinil alkohol (PVA) dengan senyawa 1,1,1,3,3,3hexamethyldisilazane (HMDS) dapat menghasilkan permukaan hidrofob dengan sudut kontak sebesar $152.3^{0}$ (Gao et al., 2016).

Pengukuran diameter zona hambat atau zona bening digunakan sebagai indikator keefektifan sampel dalam menghambat aktivitas pertumbuhan bakteri. Terbentuknya zona bening di sekitar sampel dikarenakan tidak adanya aktivitas bakteri atau artinya bakteri tidak tumbuh pada daerah tersebut. Diameter zona bening yang semakin besar menunjukkan semakin banyak bakteri yang rusak dan mati (Shateri-Khalilabad dan Yazdanshenas, 2010). Bakteri yang digunakan adalah Staphylococcus aureus karena merupakan salah satu jenis bakteri penyebab infeksi yang paling umum dijumpai, penghasil toksin berbahaya bagi manusia dan kebal terhadap antibiotik (Ariyanta et al., 2014). Staphylococcus aureus akan berasosiasi dengan kulit, kelenjar kulit dan selaput lendir hewan berdarah panas. Kisaran inangnya luas serta banyak galur dari $S$. aureus yang merupakan patogen potensial (Karimela et al., 2017). Penelitian ini bertujuan untuk mengetahui aktivitas antibakteri kain poliester yang terdeposit senyawa HDTMS terhadap pertumbuhan bakteri Gram positif yaitu Staphylococcus aureus ATCC 25924 dengan mengamati zona bening yang terbentuk di sekitar sampel. Penelitian tentang penambahan atau modifikasi kain poliester dengan senyawa HDTMS sehingga kain yang dihasilkan bersifat antibakteri belum pernah dilaporkan sebelumnya.

\section{METODE PENELITIAN}

\section{Alat dan Bahan}

Alat-alat yang digunakan dalam penelitian ini adalah timbangan analitik, hot plate, magnetic stirrer, shaker, alat-alat gelas, cawan petri, autoklaf, kawat ose, dan jangka sorong. Bahan-bahan yang digunakan meliputi kain poliester $\mathrm{AgNO}_{3}$, akuades, kertas saring Whatman No. 42, PVA, nutrient agar (NA), nutrient broth (NB), dan bakteri Staphylococcus aureus ATCC 25924.

Metode yang digunakan untuk memodifikasi poliester sehingga diperoleh sampel P-HDTMS adalah dengan cara menyelupkan sampel poliester dalam larutan 
HDTMS. Pembuatan larutan HDTMS mengikuti metode yang telah dilakukan oleh Rohaeti dan Rakhmawati (2017). Pencelupan sampel poliester dalam larutan HDTMS dilakukan selama 60 menit pada temperatur kamar dalam shaker dengan kecepatan 155 rpm.Sampel poliester yang telah dilapisi dengan larutan HDTMS dikeringkan kemudian dilanjutkan dengan proses curing pada $110^{\circ} \mathrm{C}$ selama 60 menit, sehingga diperoleh sampel PHDTMS. Uji aktivitas antibakteri dilakukan dengan metode difusi dengan mengamati zona bening yang terbentuk di sekeliling sampel (Rohaeti dan Rakhmawati, 2017).

\section{Prosedur Kerja}

Pengujian dilakukan dengan cara meletakkan sampel P-HDTMS yang dipotong bulat menggunakan pelubang kertas (diameter $\pm 0.6 \mathrm{~cm}$ ) di atas biakan bakteri Staphylococcus aureus ATCC 25924 yang sudah ditanam dalam cawan petri. Pengukuran zona bening dilakukan setelah 24 jam waktu inkubasi bakteridandilakukan selama 72 jam waktu inkubasi. Diameter zona bening di sekeliling sampel diukur menggunakan jangka sorong. Semakin besar zona bening yang diperoleh menandakan bahwa bakteri tidak tumbuh pada daerah tersebut. Dengan demikian aktivitas antibakteri kain P-HDTMS dapat ditentukan.

\section{HASIL DAN PEMBAHASAN}

Hasil dari sampel kain poliester yang telah terdeposit senyawa HDTMS terlihat lebih putih (Gambar 1) yang menandakan bahwa senyawa HDTMS telah melapisi permukaan kain poliester secara sempurna. Keberhasilan pelapisan bahan tekstil dengan senyawa HDTMS diperkuat dengan hasil pengujian sudut kontak yang menunjukkan bahwa HDTMS adalahagen yang menyebabkan kain bersifat hidrofobik (Rohaeti dan Rakhmawati, 2017).

Aktivitas antibakteri dari kain poliesterHDTMS dilakukan melalui pengukuran zona hambatnya terhadap bakteri Staphylococcus aureus ATCC 25923. Bakteri Staphylococcus aureus ATCC 25923 merupakan bakteri gram positif yang memiliki warna ungu. Bentuk dari bakteri ini bulat dan biasanya bergerombol sehingga terlihat seperti anggur. Hasil pengamatan secara mikroskopik terhadap bakteri Staphylococcus aureus ATCC 25923 dengan pengecatan gramuntuk mengetahui bentuk dan klasifikasi bakteri ditunjukkan oleh Gambar 2.
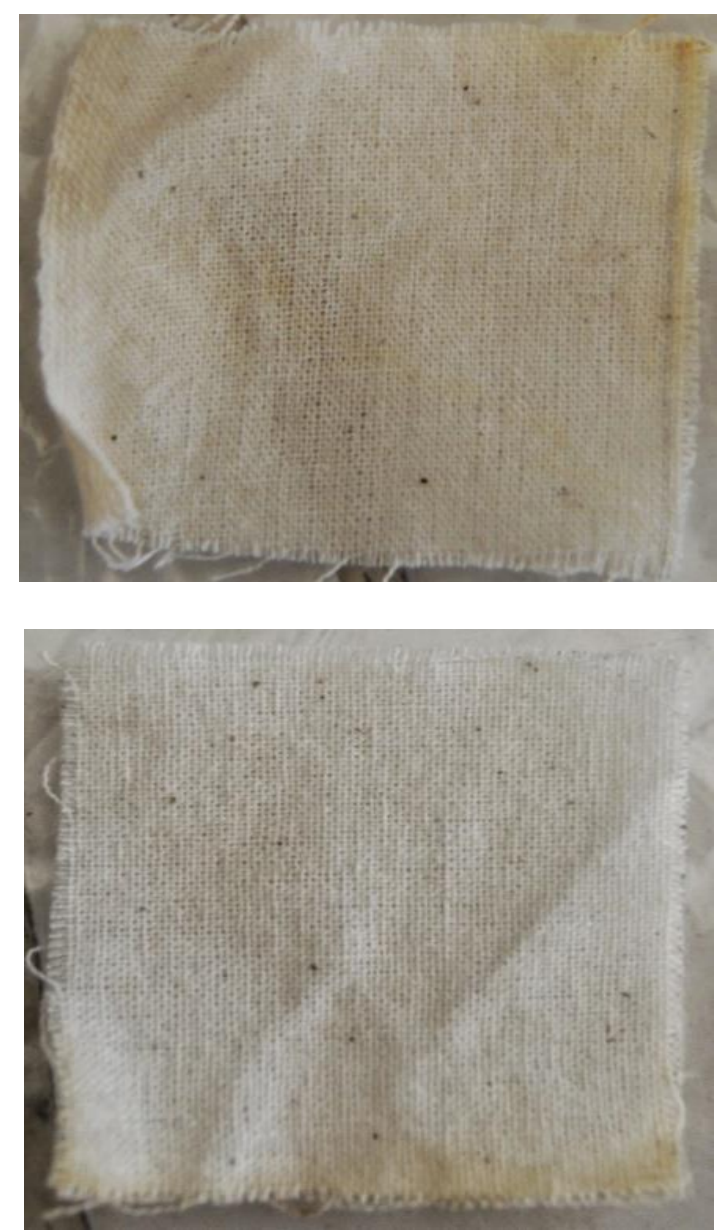

Gambar 1. Kain poliester (atas) dan kain poliester setelah dilapisi dengan larutan HDTMS (bawah)

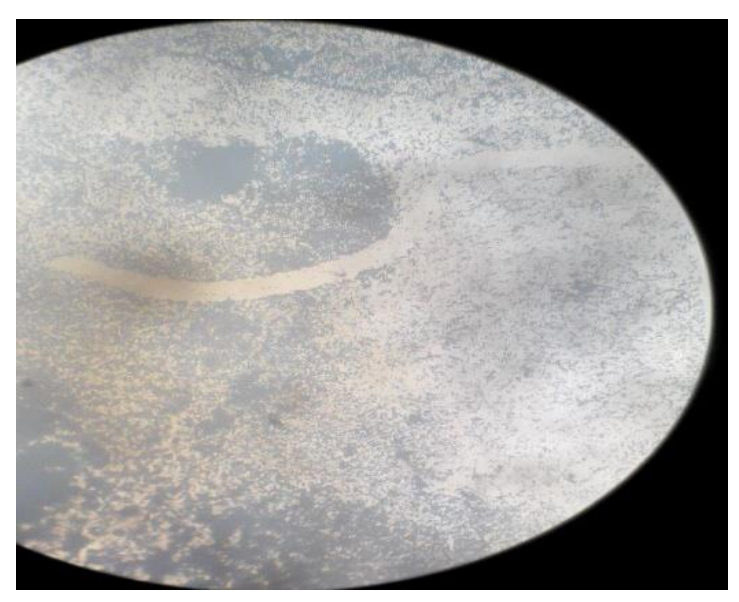

Gambar 2. Hasil pengamatan mikroskopis bakteri Staphylococcus aureus ATCC 25923 (Perbesaran 10x10) 
Tabel 1. Diameter zona bening sampel P-HDTMS terhadap bakteri Staphylococcus aureus ATCC 25924

\begin{tabular}{|c|c|c|c|c|c|c|c|c|c|c|c|c|}
\hline \multirow{2}{*}{ No } & \multirow{2}{*}{ Sampel } & \multicolumn{11}{|c|}{ Diameter zona bening pada pengamatan jam ke- $(\mathrm{mm})$} \\
\hline & & 42 & 45 & 48 & 51 & 54 & 57 & 60 & 63 & 66 & 69 & 72 \\
\hline 1 & Poliester & 6.26 & 6.45 & 7.18 & 7.39 & 7.54 & 8.04 & 8.26 & 7.61 & 7.30 & 7.04 & 6.88 \\
\hline 2 & $\begin{array}{c}\text { Poliester - } \\
\text { HDTMS }\end{array}$ & 6.80 & 7.18 & 7.28 & 7.80 & 8.16 & 8.57 & 9.25 & 8.84 & 8.47 & 7.90 & 7.58 \\
\hline
\end{tabular}

Hasil pengukuran diameter zona bening terhadap sampel poliester dan poliesterHDTMS selama 72 jam waktu inkubasi disajikan pada Tabel 1. Berdasarkan Tabel 1, sampel poliester-HDTMS menunjukkan diameter zona hambat lebih besar dibandingkan dengan sampel poliester tanpa HDTMS pada waktu inkubasi yang sama. Dengan demikian, modifikasi kain poliester dengan pelapisan menggunakan larutan HDTMS meningkatkan kemampuan kain poliester dalam menghambatpertumbuhan bakteri Staphylococcus aureus. Pelapisan HDTMS menyebabkan aktivitas antibakteri kain poliester mengalami peningkatan.

Peningkatan aktivitas antibakteri setelah kain poliester dimodifikasi dengan HDTMS dapat disebabkan karena senyawa HDTMS termasuk ke dalam senyawa organosilan. Kebanyakan dari senyawa organosilan memiliki satu substituen organik dan tiga substituen yang kurang stabil sehingga mudah dihidrolisis. HDTMS memiliki substituen berupa gugus metoksisilan yang mudah mengalami hidrolisis membentuk gugus hidroksil. Selanjutnya HDTMS yang terhidrolisis akan berkondensasi dengan gugus hidroksil kain poliester dan membentuk ikatan hidrogen sehingga membentuk gugus fungsi yang hidrofob. Adanya gugus yang hidrofob tersebut menyebabkan bakteri sulit berinteraksi dengan serat poliester dan terjadi peningkatan aktivitas antibakteri dari kain poliester sesudah dimodifikasi dengan HDTMS. Reaksi pelapisan permukaan materi menggunakan senyawa organosilan ini terbagi menjadi empat bagian seperti pada Gambar 3 .

Pertama, reaksi hidrolisis yang terjadi pada ketiga substituen kurang stabil, kemudian tahap kedua terjadi reaksi kondensasi membentuk oligomer (Kusuktham, 2010). Tahap ketiga, senyawa oligomer ini kemudian membentuk ikatan hidrogen dengan gugus $\mathrm{OH}$ yang terdapat pada ujung rantai poliester. Tahap keempat, ketika pengeringan atau reaksi curing berlangsung, $\mathrm{H}_{2} \mathrm{O}$ akan terlepas dan terbentuk ikatan kovalen antara senyawa oligomer dengan substrat (Arkles, 2006).

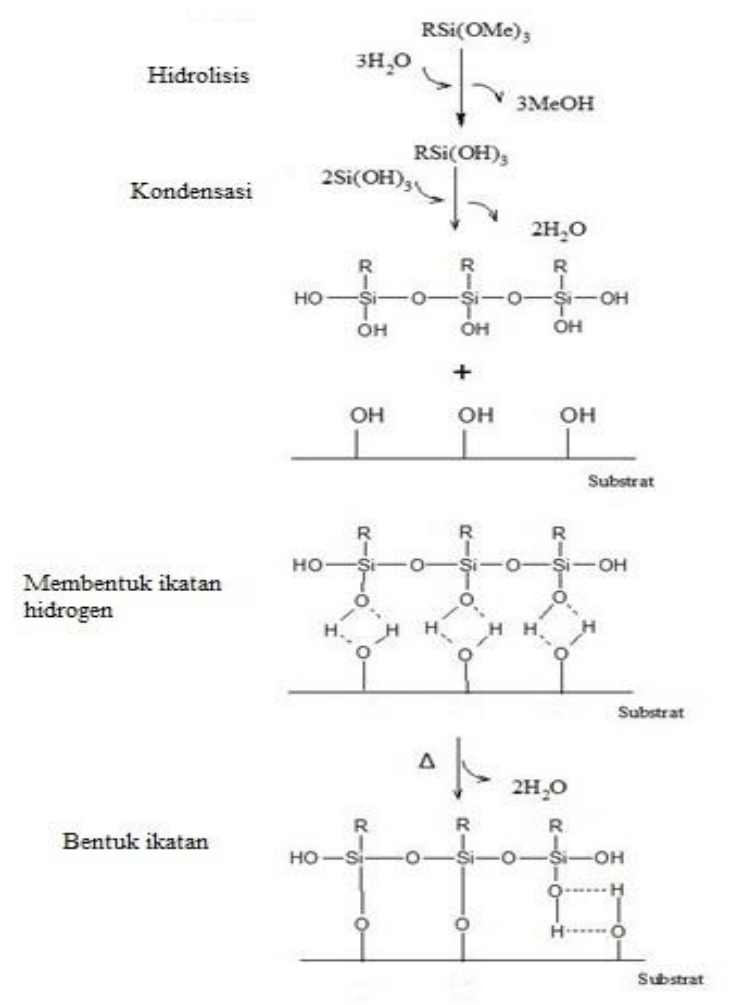

Gambar 3. Reaksi pelapisan senyawa silan (Arkles, 2006)

Penambahan senyawa HDTMS telah memberikan efek penghambatan terhadap pertumbuhan bakteri. Pengaruh senyawa HDTMS dapat menghambat pertumbuhan bakteri kemungkinan dapat dikarenakan sifat senyawa HDTMS mirip dengan detergen yaitu memiliki gugus fungsi yang bersifat hidrofilik dan hidrofobik, Selain itu senyawa HDTMS juga dapat menurunkan tegangan permukaan sama seperti detergen. Menurut Rama et al., (2011), detergen yang mengandung gugus hidrofilik dan hidrofobik merupakan bahan antibakteri yang dapat merusak membran sitoplasma dan membunuh sel bakteri. Gao et al., (2009) mengungkapkan bahwa pelapisan permukaan kain dengan HDTMS 
menyebabkan kain sulit dihidrolisis pada proses pencucian yang berulang kali. Dengan demikian, penambahan HDTMS dapat meningkatkan sifat hidrofobik dari permukaan kain yang dilapisi, sehingga bakteri sulit hidup pada permukaan kain tersebut.

Penghambatan mulai terjadi pada saat waktu inkubasi bakteri $42 \mathrm{jam}$, hal tersebut ditandai dengan mulai teramatinya zona bening. Bakteri mulai memasuki fase perbanyakan pada waktu inkubasi 42 jam. Zona bening tidak teramati saat waktu inkubasi 24 jam dan 30 jam, hal ini dimungkinkan pada waktu tersebut bakteri masih dalam fase adaptasi. Memasuki waktu inkubasi 66 jam zona bening yang teramati mengalami penurunan yang cukup tajam, hal ini disebabkan karena bakteri sudah memasuki fase kematian.

Penambahan senyawa HDTMS juga memberikan efek penghambatan terhadap pertumbuhan bakteri. Senyawa HDTMS mempunyai gugus metoksi $\left(-\mathrm{OCH}_{3}\right)_{3}$ (Fisk dan Disley, 2011) yang berubah menjadi gugus hidroksil $(-\mathrm{OH})_{3}$ setelah terjadi reaksi hidrolisis, gugus hidroksil $(-\mathrm{OH})$ dapat menghambat proses pembentukan ATP, karena senyawa hidroksil dalam HDTMS akan bereaksi dengan fosfat sehingga mengganggu proses pembentukan energi pada bakteri, hal tersebut yang menyebabkan pertumbuhan bakteri menjadi terhambat (Agnihotri et al., 2014). Aktivitas antibakteri tertinggi pada penelitian ini dimiliki oleh sampel kain poliester sesudah dimodifikasi dengan larutan HDTMS pada waktu inkubasi selama 60 jam dengan diameter zona hambat sebesar 9.25 $\mathrm{mm}$.

\section{SIMPULAN}

Hasil uji aktivitas antibakteri menunjukkan bahwa sampel kain poliester yang dilapisi senyawa HDTMS mempunyai aktivitas antibakteri lebih baik dibandingkan kain poliester dalam menghambat pertumbuhan bakteri gram positif berupa Staphylococcus aureus ATCC 25923. Poliester hasil modifikasi dengan larutan HDTMS pada waktu inkubasi selama 60 jam menunjukkan aktivitas antibakteri paling tinggi. Dengan demikian modifikasi kain poliester dengan senyawa HDTMS dapat meningkatkan sifat antibakteri kain poliester. HDTMS memberikan efek penghambatan terhadap pertumbuhan bakteri.

\section{DAFTAR PUSTAKA}

Agnihotri S, Mukherji S, Mukherji S. 2014. Sizecontrolled silver nanoparticles synthesized over the range 5-100 $\mathrm{nm}$ using the same protocol and their antibacterial efficacy $R S C$ Adv. 4(1): 3974-3983.

Ariyanta HA, Wahyuni S, Priatmoko S. 2014. Preparasi nano partikel perak dengan metode reduksi dan aplikasinya sebagai antibakteri penyebab infeksi. Indonesian Journal of Chemical Science. 3(1): 1-6.

Arkles B. 2006. Hydrophobicity, hydrophilicity and silanes. Paint and Coating Industry.22(10): 114-124.

El-Khatib EM. 2012. Antimicrobial and selfcleaning textiles using nanotechnology. Research Journal of Textile and Apparel. 16(3): 156-174.

Fisk P, Disley H. 2011. Reconsile Consortium: Substance identification profile for Hexadecyltrimethoxysilane.www.reachcen trum.eu/Consortia\%20Documents/. pada tanggal 20 September 2015 pukul 21.20

Gao S, Watanabe H, Nakane K, Zhao K. 2016. Fabrication and characterization of superhydrophobic and superhydrophilic silica nanofibers mats with excellent heat resistance. Journal of Mining and Metallurgy, Section B: Metallurgy. 52(1): 87-92.

Gao Q, Zhu Q, Guo Y. 2009. Formation of highly hydrophobic suface on cotton and polyester fabrics using silica sol nanoparticles and nonfluorinated alkylsilane. Ind Eng Chem Res. 48(1): 9797-9803.

Karimela EJ, Ijong FG, Dien HA. 2017. Karakteristik Staphylococcus aureus yang diisolasi dari ikan asap pinekuhe hasil olahan tradisional Kab. Sangihe. JPHPI. 20(1): 188-198.

Kusuktham B. 2010. Surface modification of polyester fabrics with vinyltriethoxysilane. Journal of Metals, Materials and Minerals. 20(2): $85-88$ 
Rama BP, Prajna PS, Menezez VP, Shetty P. 2011. Antimicrobial activities of soap and detergents. Adv.In Bioresearch. 2(2): 52-62.

Rohaeti E, Rakhmawati A. 2017. Antibacterial activity and the hydrophobicity of cotton coated with hexadecyltrimethoxysilane. AIP Conference Proceedings. The American Institute of Physics. http://dx.doi.org/10.1063/1.4995096.

Shateri-Khalilabad M, Yazdanshenas ME. 2010. Super hydrophobic antibacterial cotton textiles. 351(1): 293-298.
Shateri-Khalilabad M, Yazdanshenas ME. 2013. One-pot sono chemical synthesis of super hydrohpobic organic-inorganic hybrid coating on cotton. Cellulose. 20(1): 30393051 .

Xue CH, Chen J, Yin W, Jia ST, Ma. 2012. Super hydrophobic condictive textiles with antibacterial property by coating fibers with silver nano particles. Applied Surface Science. 258(1): 2468-2472. 